\title{
The year in cardiology 2016: acute coronary syndromes
}

\author{
Filippo Crea ${ }^{1}$, Ronald K. Binder ${ }^{2}$, Thomas F. Lüscher ${ }^{2}$ \\ ${ }^{1}$ Department of Cardiovascular and Thoracic Sciences, Institute of Cardiology, Catholic University, Largo A. Gemelli, \\ 8-00168 Rome, Italy, ${ }^{2}$ Department of Cardiology, University Heart Center, University Hospital Zurich, Raemstrasse 100, \\ 8091 Zurich, Switzerland.
}

The opinions expressed in this article are not necessarily those of the Editors of the European Heart Journal or of the European Society of Cardiology.

Copyright: Crea F, Binder RK, Lüscher TF. The year in cardiology 2016: acute coronary syndromes. Eur Heart J 2017; 38 (3): 154-164. doi: 10.1093/eurheartj/ehw620, Published on behalf of the European Society of Cardiology. All rights reserved. (C) The Author 2017. For permissions, please email: journals.permissions@oup.com

Drug and Material Disclaimer: The mention of trade names, commercial products organizations, and the inclusion of advertisements in the journal does not imply endorsement by the European Heart Journal, the editors, the editorial board, Oxford University Press or the organization to which the authors are affiliated. The editors and publishers have taken all reasonable precautions to verify drug names and doses, the results of experimental work and clinical findings published in the journal. The ultimate responsibility for the use and dosage of drugs mentioned in the journal and in interpretation of published material lies with the medical practitioner, and the editors and publisher cannot accept liability for damages arising from any error or omissions in the journal. Please inform the editors of any errors. The opinions expressed in the European Heart Journal are those of the authors and contributors, and do not necessarily reflect those of the European Society of Cardiology, the editors, the editorial board, Oxford University Press or the organization to which the authors are affiliated.

\section{Preamble}

T he year 2016 brought us several studies on the pathophysiology of acute coronary syndrome (ACS), in particular, on the role of basophils and eosinophils in the mechanism of disease. New puzzling data have also emerged on the pathomechanisms of very late stent thrombosis and the role of neutrophils in ventricular remodelling. New information has also been published on the early diagnosis of ACS by high sensitivity troponin (hsTn) and the role of new exciting biomarkers and clinical scores on risk stratification. With regards to antithrombotic treatment, the year 2016 has brought important new data on the duration of dual antiplatelet therapy (DAPT) and on the management of the growing population of very elderly. Finally, new interesting information has been published on the outcome of specific patient subsets. The studies reported in this review are summarized in Table 1.

\section{Mechanisms}

\section{Pathogenesis of ACS}

Spontaneous ACS can be caused by plaque fissure, plaque erosion, or functional alterations of epicardial coronary arteries or by vasoconstriction of the microcirculation. Activation of inflammatory cells plays a key role in both plaque fissure and erosion although the mechanisms leading to plaque instability are substantially different in these two conditions. Indeed, while monocyte and lymphocyte activation is the key alteration in plaque fissure, neutrophil activation is a crucial player in plaque erosion. The role of eosinophil and basophil activation is still largely unknown. Niccoli et al. ${ }^{1}$ found a higher degree of both eosinophil and basophil activation, as assessed by flow cytometry, in patients with ACS than in those with stable angina. Furthermore, in a prospective cohort study they found that higher levels of eo- sinophil cationic protein (ECP) were associated with a worse outcome during follow-up. This suggests that novel therapies targeting eosinophils should be tested in ACS patients exhibiting raised ECP levels.

\section{Stent thrombosis}

It is well known that very late stent thrombosis is a possible cause of ACS. The pathomechanisms underlying very late stent thrombosis after implantation of drugeluting stents (DES) are incompletely understood. Using optical coherence tomography (OCT), Taniwaki et al. ${ }^{2}$ investigated potential causes of this adverse event. They found that the leading associated findings in very late stent thrombosis were in descending order: (i) stent malapposition, (ii) neoatherosclerosis, (iii) uncovered stent struts, and (iv) stent underexpansion. The longitudinal extension of malapposed and uncovered struts was the most important correlate of thrombus formation. These findings might further expand the clinical utilization of OCT in optimizing the results of stent implantation.

\section{Remodelling}

Another important issue in ACS are the mechanisms responsible for left ventricular remodelling after myocardial infarction (MI). In an elegant experimental study in a mice model of MI, Horckmans et al. ${ }^{3}$ found that neutrophil-depleted animals had worsened cardiac function, increased fibrosis, and progressively developed heart failure. Thus, while high neutrophil counts are considered as predictor of adverse clinical outcomes and mortality in patients with ACS and their contribution in the acute inflammatory phase after $\mathrm{MI}$ is generally considered detrimental, these data suggest that neutrophils participate in $\mathrm{MI}$ repair skewing macrophages towards a resolving phenotype, which mediates efficient clearance of cell debris. This novel role for neutrophils should be taken in 
Table 1. Summary of the main studies.

\begin{tabular}{|c|c|c|}
\hline Topic & Main messages & References \\
\hline Mechanisms & $\begin{array}{l}\text { - Allergic immunity is altered in ACS } \\
\text { - VLST is frequently associated to suboptimal stent implantation } \\
\text { - In experimental models neutrophil depletion is associated to worse } \\
\text { remodelling }\end{array}$ & $\begin{array}{l}\text { - Niccoli } \\
\text { - Taniwaki } \\
\text { - Horckmans }\end{array}$ \\
\hline Early diagnosis & $\begin{array}{l}\text { - The best hsTn algorithm to rule out ACS remains controversial } \\
\text { - Potential role of micro-RNA } \\
\text { - The role of coronary computed tomography angiography in the emergency } \\
\text { department in patients with suspected ACS is limited }\end{array}$ & $\begin{array}{l}\text { - Pickering } \\
\text { Shah } \\
\text { - Coskunpinar } \\
\text { - Dedic }\end{array}$ \\
\hline Risk stratification & $\begin{array}{l}\text { - GDF-15 predicts both bleeding and ischemic risk } \\
\text { - New clinical risk scores to predict in-hospital mortality and medium-term risk } \\
\text { of sudden cardiac death in patients admitted with ACS }\end{array}$ & $\begin{array}{l}\text { - Hagstrom } \\
\text { - Hess } \\
\text { - He }\end{array}$ \\
\hline Treatment & $\begin{array}{l}\text { - The efficacy of Cangrelor compared to clopidogrel previously found in the } \\
\text { CHAMPION PHOENIX trial is independent of the puncture site } \\
\text { - The pharmacodynamic effects of Ticagrelor are impaired by morphine } \\
\text { - Data from SWEDEHEART database confirm the better efficacy of Ticagrelor as } \\
\text { compared to Clopidogrel in ACS in the real world } \\
\text { - The pharmacodynamic effects of crushed Prasugrel tablets are better than } \\
\text { those of intact tablets } \\
\text { - A meta-analysis suggests that dual antiplatelet therapy beyond one year after } \\
\text { ACS reduces subsequent ischemic events } \\
\text { - The addition of ezetimibe to simvastatin reduced first and subsequent } \\
\text { cardiovascular events in ACS patients in the IMPROVE-IT trial } \\
\text { - A sub-study of the LEADERS FREE trial confirms that Biolimus-A9 polymer-free } \\
\text { coated stent is superior to bare metal stent in ACS patients with high-bleeding } \\
\text { risk on one-month double antiplatelet treatment } \\
\text { - A real-world analysis fails to show superiority of bivaluridin as compared to } \\
\text { other anti-thrombotic treatments } \\
\text { - The efficacy of early beta-blockers in STEMI remains controversial } \\
\text { - In early STEMI admitted to non-capable PCI centres, transfer for primary PCI is } \\
\text { better than fibrinolysis if the delay is less than } 140 \text { min } \\
\text { - In NSTEMI a single-staged compared with a multi-staged PCI is associated with } \\
\text { a lower rate of target vessel revascularization during follow-up } \\
\text { - In the very elderly with ACS, an invasive approach is associated to a better } \\
\text { outcome as compared to a conservative approach } \\
\text { - PCI in unprotected left main stenosis is associated with comparable clinical } \\
\text { outcomes to those observed with coronary artery grafting at long-term follow-up } \\
\text { - The outcome of left ventricular assist device implanted in patients with ACS is } \\
\text { similar to that observed in stable patients }\end{array}$ & 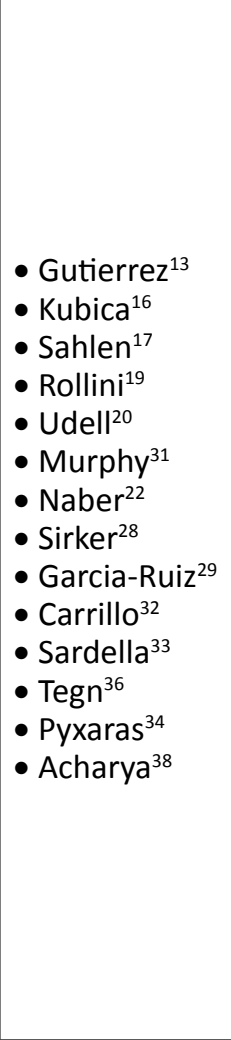 \\
\hline $\begin{array}{l}\text { Outcomes in } \\
\text { specific patient } \\
\text { populations }\end{array}$ & $\begin{array}{l}\text { - Women: a statement from the American Heart Association on ACS in women } \\
\text { summarizes the main differences between men and women in this setting. } \\
\text { - Smokers: smoking is independently associated to better left ventricular } \\
\text { remodelling } \\
\text { - Rheumatoid arthritis: among patients with ACS rheumatoid arthritis is } \\
\text { associated to a worse outcome } \\
\text { - Vasospastic angina: among patients with vasospastic angina those who present } \\
\text { with aborted sudden cardiac death have a worse outcome during follow up } \\
\text { - Takotsubo syndrome: the outcome of the "happy heart syndrome" is similar to } \\
\text { that of the "broken heart syndrome" }\end{array}$ & $\begin{array}{l}\text { - Mehta }{ }^{39} \\
\text { - Symons }{ }^{40} \\
\text { - Mantel }{ }^{41} \\
\text { - Ahn }{ }^{42} \\
\text { - } \text { Ghadri }^{44}\end{array}$ \\
\hline
\end{tabular}

ACS, acute coronary syndrome; NSTEMI, non-ST elevation myocardial infarction; PCI, percutaneous coronary intervention; STEMI, ST elevation myocardial infarction; VLST, very late stent thrombosis.

account when designing and applying 'aggressive' antineutrophil treatments in the setting of $\mathrm{MI}$.

\section{Early diagnosis}

\section{Troponins}

The evaluation of patients presenting at the emergency department (ED) with suspected ACS remains a clinical challenge. The traditional assessment includes clinical risk assessment based on symptoms, cardiovascular (CV) risk factors with serial electrocardiograms and hsTn measurements, often followed by advanced cardiac testing as inpatients or outpatients. With regards to hsTn, several cohort studies have shown that patients with undetectable plasma hsTn concentrations at presentation are at low risk of MI. However, the optimal approach and threshold of hsTn for the identification of low-risk patients suitable for immediate discharge is still 
debated. Shah et al. ${ }^{4}$ did a prospective cohort study of 6304 consecutively enrolled patients with suspected ACS presenting to 4 secondary and tertiary care hospitals in Scotland. They measured plasma Tn concentrations at presentation using a hsTnl assay and evaluated the negative predictive value of a range of hs Tnl concentrations for the primary outcome of index $\mathrm{MI}$, or subsequent $\mathrm{MI}$ or cardiac death at 30 days in derivation and validation cohorts. The median time from arrival in the ED to blood sampling for measurement of hsTn was $54 \mathrm{~min}$. They found that a hsTn concentration of less than $5 \mathrm{ng} / \mathrm{L}$ at presentation met their pre-specified criteria for a negative predictive value of at least $99.5 \%$. At this threshold, almost two-thirds of patients with suspected ACS could have been discharged with very few cardiac events. Indeed, implementation of this threshold could double the number of patients discharged directly from the ED.

In one study, Pickering et al. ${ }^{5}$ tested the $0-1 \mathrm{~h}$ rule out algorithm proposed by the current European Guidelines on 2015 ESC guidelines for the management of ACS in patients presenting without persistent ST-segment elevation, in 2222 patients with serial hsTnT and hsTnl measurements. The 0-1 h hsTnT algorithm ruled out 1425 patients $(64.1 \%)$ with a sensitivity of $97.1 \%$. The 0-1 h hsTnl algorithm ruled out 1205 patients (54.2\%) with a sensitivity of $98.8 \%$. They concluded that the sensitivity of the European Society of Cardiology rapid assessment $0-1 \mathrm{~h}$ algorithm to rule-out AMI with highsensitivity troponin may be insufficient for some ED physicians to confidently send patients home. Thus, the identification of the optimal rule-out hsTn algorithm in patients with suspected ACS admitted to ED remains debated as well as the optimal rule-in algorithm. ${ }^{6}$ Also controversial is the utilization of a second biomarker like copeptin.

With regards to new biomarkers in the early diagnosis of ACS, in a proof of concept study Coskunpinar et al. ${ }^{7}$ assessed the potential diagnostic role of circulating micro-RNAs in patients with ACS. They found that miR221-3p was significantly positively correlated with Tn levels, GRACE and SYNTAX Score and inversely correlated with post-MI left ventricular systolic function. They conclude that miR-221-3p may be a promising biomarker for early diagnosing of ACS.

\section{Coronary computed tomography angiography}

It is uncertain whether a diagnostic strategy supplemented by early coronary computed tomography angiography (CCTA) is superior to contemporary standard optimal care including hsTn for patients suspected of ACS in the ED. In a prospective, open-label, multicentre, randomized trial, Dedic et al. ${ }^{8}$ enrolled 500 patients presenting with symptoms suggestive of an ACS at the ED of 5 community and 2 university hospitals in the Netherlands. The primary endpoint was the number of patients identified with significant coronary artery disease requiring revascularization within 30 days. There was no difference in the primary endpoint. Discharge from the
ED was not more frequent after CCTA and length of stay was similar. The authors conclude that in the era of hsTns, CCTA does not identify more patients with significant CAD requiring coronary revascularization, neither does it shorten hospital stay, or allow for more direct discharge from the ED.

\section{Risk stratification}

\section{Clinical scores}

McNamara et al. ${ }^{9}$ using the ACTION (Acute Coronary Treatment and Intervention Outcomes Network) Registry-GWTG (Get With the Guidelines) database developed a multivariate hierarchical logistic regression model predicting in-hospital mortality. The population (243 440 patients from 655 hospitals) was divided into a $60 \%$ sample for model derivation, with the remaining $40 \%$ used for model validation. A simplified risk score was created to enable prospective risk stratification in clinical care. Age, heart rate, systolic blood pressure, presentation after cardiac arrest, presentation in cardiogenic shock, presentation in heart failure, presentation with ST-segment elevation $\mathrm{Ml}$, creatinine clearance, and Tn ratio were all independently associated with in-hospital mortality. Observed mortality rates varied substantially across risk groups, ranging from $0.4 \%$ in the lowest risk group (score $<30$ ) to $49.5 \%$ in the highest risk group (score $>59$ ). This work built upon and extended prior mortality risk models developed for patients with AMI. Although valuable for the selected populations at the time of their original development, changes in patient profiles and AMI management demand updating. The new risk score might serve this purpose.

In a pooled cohort analysis which merged individual data from 48286 participants in 4 trials Hess et al. ${ }^{10}$ found that sudden cardiac death (SCD) accounted for about one-third of CV deaths during 1-year follow-up and that reduced left ventricular ejection fraction, older age, diabetes mellitus, lower estimated glomerular filtration rate, higher heart rate, prior MI, peripheral artery disease, Asian race, male sex, and high Killip class were significantly associated with SCD. They also developed an integer-based score from this model, which yielded a calculated SCD probability ranging from 0.1 to $56.7 \%$. This score might help in the identification of candidates for implantable cardioverter defibrillators above and beyond the mere assessment of ejection fraction although prospective assessment of device therapy is warranted because not all sudden death is arrhythmic and may in fact stem from other causes such as recurrent $\mathrm{MI}$ or cardiac rupture.

\section{Biomarkers}

Hagstrom et $a l .{ }^{11}$ assessed independent associations between growth differentiation factor-15 (GDF-15) levels and major bleeding and CV events in patients with ACS patients randomized to ticagrelor or clopidogrel in the PLATO (PLATelet inhibition and patient Outcomes) trial. In Cox proportional hazards models adjusting for established risk factors for CV disease and prognostic 


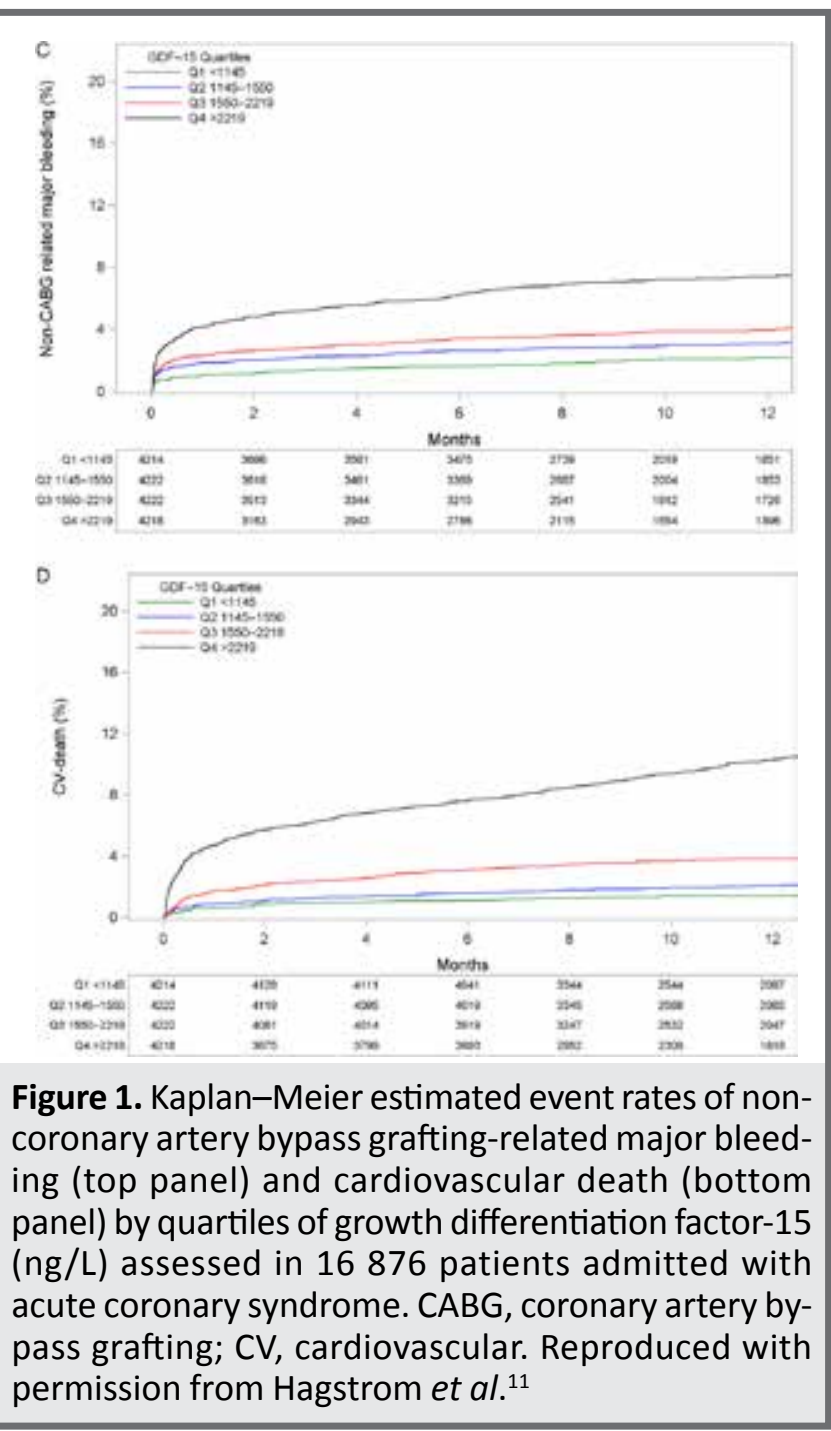

Gutierrez JA, et al. The effect of cangrelor and access site on ischaemic and bleeding events: insights from CHAMPION PHOENIX. Eur Heart J 2016; 37 (14): 1122-1130. doi: 10.1093/eurheartj/ehv498.

Reprinted with permission of Oxford University Press on behalf of the European Society of Cardiology.

biomarkers ( $\mathrm{N}$-terminal pro B-type natriuretic peptide, cystatin C, high-sensitive C-reactive protein, and hsTn), GDF-15 was associated with increased risk of major bleeding and of the composite of CV death, spontaneous $\mathrm{MI}$, and stroke. The mechanism for the association between GDF-15 and the risk of bleeding might be related to an inhibitory effect on platelet activation mediated via a mechanism similar to glycoprotein IIb/IIla inhibition resulting in a lower ability of the cells to form a thrombus. These findings give further support to the utilization of this biomarker in the clinical setting of ACS (Figure 1).

\section{Treatments}

Mechanical reperfusion of the infarct-related artery by percutaneous coronary intervention ( $\mathrm{PCl}$ ) and adjunctive medical management including antithrombotic therapy remain the cornerstones of current ACS management.

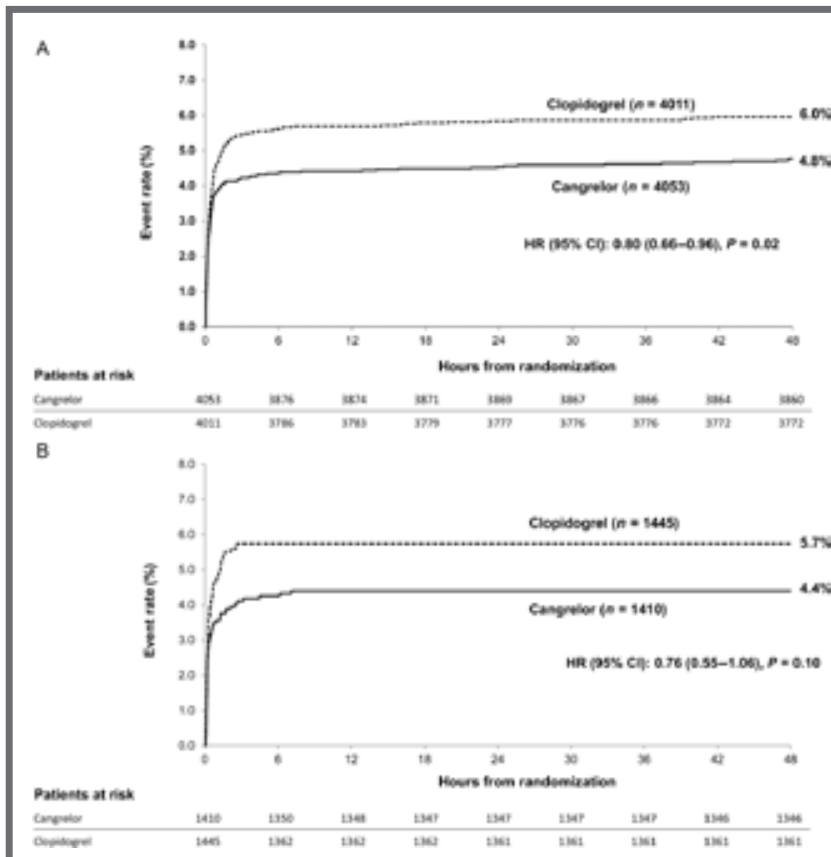

Figure 2. In the CHAMPION PHOENIX trial, Gutierrez et al. ${ }^{13}$ analysed among 11145 patients whether the femoral or radial approach for $\mathrm{PCl}$ interacted with the efficacy and safety of cangrelor. $(A)$ Kaplan-Meier curves for the primary efficacy endpoint in the subgroup undergoing femoral access (cangrelor vs. clopidogrel). (B) Kaplan-Meier curves for the primary efficacy endpoint in the subgroup undergoing radial access (cangrelor vs. clopidogrel). HR, hazard ratio; $\mathrm{Cl}$, confidence interval. Reproduced with permission from Gutierrez et al. ${ }^{13}$

Gutierrez JA, et al. The effect of cangrelor and access site on ischaemic and bleeding events: insights from CHAMPION PHOENIX. Eur Heart J 2016; 37 (14): 1122-1130. doi: 10.1093/eurheartj/ehv498.

Reprinted with permission of Oxford University Press on behalf of the European Society of Cardiology.

\section{P2Y 12 inhibitors}

Recently the first intravenous $\mathrm{P}_{2} \mathrm{Y}_{12}$ inhibitor, Cangrelor, was approved and broadened the armamentarium of antiplatelet agents in patients undergoing $\mathrm{PCl}$. In the CHAMPION PHOENIX trial ${ }^{12}$ Gutierrez et al..$^{13}$ analysed whether the femoral or radial approach for $\mathrm{PCl}$ interacted with the efficacy and safety of cangrelor. Among 11145 patients randomly assigned to cangrelor or clopidogrel at the time of $\mathrm{PCl}$ the primary endpoint, a composite of death, $\mathrm{MI}$, ischemia-driven revascularization, or stent thrombosis (Figure 2), occurred in the femoral cohort in $4.8 \%$ with cangrelor vs. $6.0 \%$ with clopidogrel (odds ratio, OR [95\% confidence interval, $\mathrm{Cl}$ ]: 0.79 [0.65$0.96]$ ); in the radial cohort, the primary endpoint was $4.4 \%$ with cangrelor vs. $5.7 \%$ with clopidogrel (OR [95\% $\mathrm{CI} 0.76$ [0.54-1.06]). $P$ for interaction was not significant. The absolute rate of bleedings tended to be lower with radial access.

The pharmacodynamics and pharmacokinetics of oral antiplatelet drugs, particularly $\mathrm{P}_{2} \mathrm{Y}_{12}$ inhibitors may be affected by absorption and first pass metabolism. Fur- 


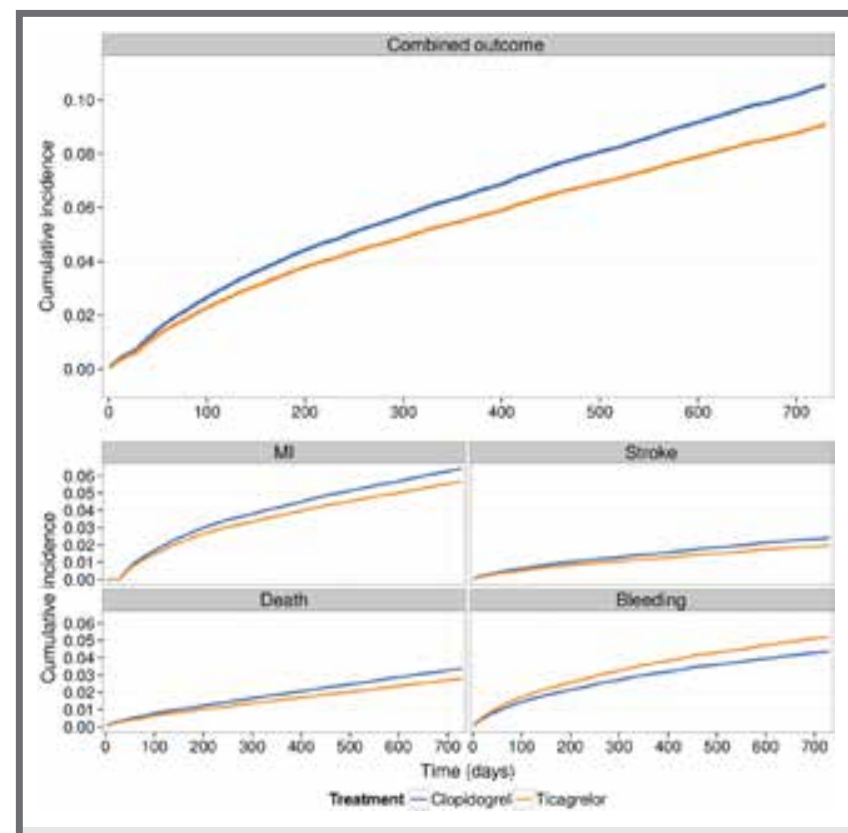

Figure 3. Incidence for the primary combined outcome of death, myocardial infarction, or stroke in 45073 ACS patients from the SWEDEHEART registry. Bottom panels show the individual components of the primary outcome, as well as the primary bleeding outcome of hospitalization with bleeding (bottom right). Treatment with clopidogrel is shown in blue and ticagrelor in yellow. Reproduced with permission from Sahlen et al. ${ }^{17}$

Sahlén A, et al. Outcomes in patients treated with ticagrelor or clopidogrel after acute myocardial infarction: experiences from SWEDEHEART registry. Eur Heart J 2016; 37 (44): 3335-3342. doi: 10.1093/eurheartj/ehw284.

Reprinted with permission of Oxford University Press on behalf of the European Society of Cardiology.

thermore, a drug-drug interaction between morphine and oral $\mathrm{P}_{2} \mathrm{Y}_{12}$ receptor inhibitors, when administered together, has been suggested. ${ }^{14,15}$ In a randomized double-blind trial, Kubica et al. ${ }^{16}$ investigated the pharmacokinetics and pharmacodynamics of ticagrelor when administered with or without intravenous morphine in ACS patients. In 70 randomized patients, morphine lowered the total exposure to ticagrelor and its active metabolite by $36 \%$ (AUC (0-12): 6307 vs. $9791 \mathrm{ng} \mathrm{h} / \mathrm{mL}$; $P=0.003$ ), and $37 \%$, respectively (AUC(0-12): 1503 vs. $2388 \mathrm{ng} \mathrm{h} / \mathrm{mL} ; P=0.008$ ). Despite this impressive interaction, the clinical significance remains to be determined.

Concurrently, an analysis of 45073 ACS patients from the SWEDEHEART registry ${ }^{17}$ compared the outcomes of those treated with ticagrelor vs. those receiving clopidogrel. After 2 years, treatment with ticagrelor was associated with a lower rate of death $(5.8 \%$ vs. $12.9 \%$, adjusted hazard ratio [HR] 0.83 [0.75-0.92]) and a lower rate of MI (6.1 vs. $10.8 \%$, adjusted HR 0.89 [0.781.01]) compared to clopidogrel (Figure 3). These realworld findings were consistent with previous randomized trial results. ${ }^{18}$

In STEMI patients undergoing primary $\mathrm{PCl}$ delayed antiplatelet effects of oral $\mathrm{P}_{2} \mathrm{Y}_{12}$ inhibitors, including prasugrel, have been observed. Rollini et al. ${ }^{19}$ investigated the bioavailablity of crushed prasugrel tablets vs. whole prasugrel tablets. The study showed that compared with whole tablets, crushed prasugrel led to reduced $\mathrm{P} 2 \mathrm{Y}_{12}$ reaction units by 30 min post-loading dose, which persisted at 1, 2, and $4 \mathrm{~h}$ post-loading dose. Thus, in STEMI patients undergoing primary $\mathrm{PCl}$, crushed prasugrel leads to faster drug absorption, and consequently, more prompt and potent antiplatelet effects compared with whole tablet ingestion. Whether this observation may be associated with clinical endpoints (e.g. acute stent thrombosis) needs to be determined in larger cohorts.

\section{Optimal dual antiplatelet treatment duration}

The optimal duration of DAPT after PCl in the setting of ACS is continuously debated as patients considered at high risk of bleeding may benefit from a shortened DAPT duration. In contrast, subsequent ischemic events in stable post ACS patients may be reduced by prolonged DAPT beyond 1 year, as was suggested in a meta-analysis. ${ }^{20}$ However, major bleeding occurs significantly more often under prolonged DAPT.

In a randomized trial, a Biolimus-A9 drug coated stent (DCS) has shown better outcomes with only one month DAPT compared to a bare metal stent (BMS) in patients at high-bleeding risk. ${ }^{21} \mathrm{~A}$ sub-study focusing on patients with $\mathrm{ACS}^{22}$ was consistent with the overall findings. At 12-month follow-up, treatment with the DCS in ACS patients was more effective (clinically driven target-lesion revascularization $3.9 \%$ vs. $9.0 \%, P=0.009$ ) and safer (cumulative incidence of cardiac death, $\mathrm{MI}$, or definite or probable stent thrombosis $9.3 \%$ vs. $18.5 \%, P=0.001$ ), than the BMS despite one month DAPT in both groups (Figure 4). As the DCS exhibited a better safety and efficacy profile than BMS, the use of BMS has to be questioned for the treatment of coronary artery stenosis. However, the lower cost of the BMS is a favourable argument in an environment with limited resources.

\section{Bivalirudin}

In primary PCI for ST-segment elevation MI (STEMI), the HORIZONS trial ${ }^{23}$ had previously shown a mortality benefit for bivalirudin over heparin with glycoprotein inhibitors (GPI). Subsequent trials ${ }^{24-27}$ comparing bivalirudin with other anti-thrombotic strategies rendered divergent results. Now a real-world analysis of 61136 patients from the UK national PCI registry ${ }^{28}$ from 2008 to 2012 showed no significant difference in short- or medium-term mortality between STEMI patients treated with bivalirudin vs. heparin and GPI at primary $\mathrm{PCl}$. Larger randomized trials will be needed to settle the role of bivalirudin vs. heparin in primary $\mathrm{PCl}$.

\section{Beta-blockade}

The impact of intravenous beta-blockers before primary $\mathrm{PCl}$ on clinical outcomes and infarct size is not well established. A post hoc analysis from the METOCARD- 


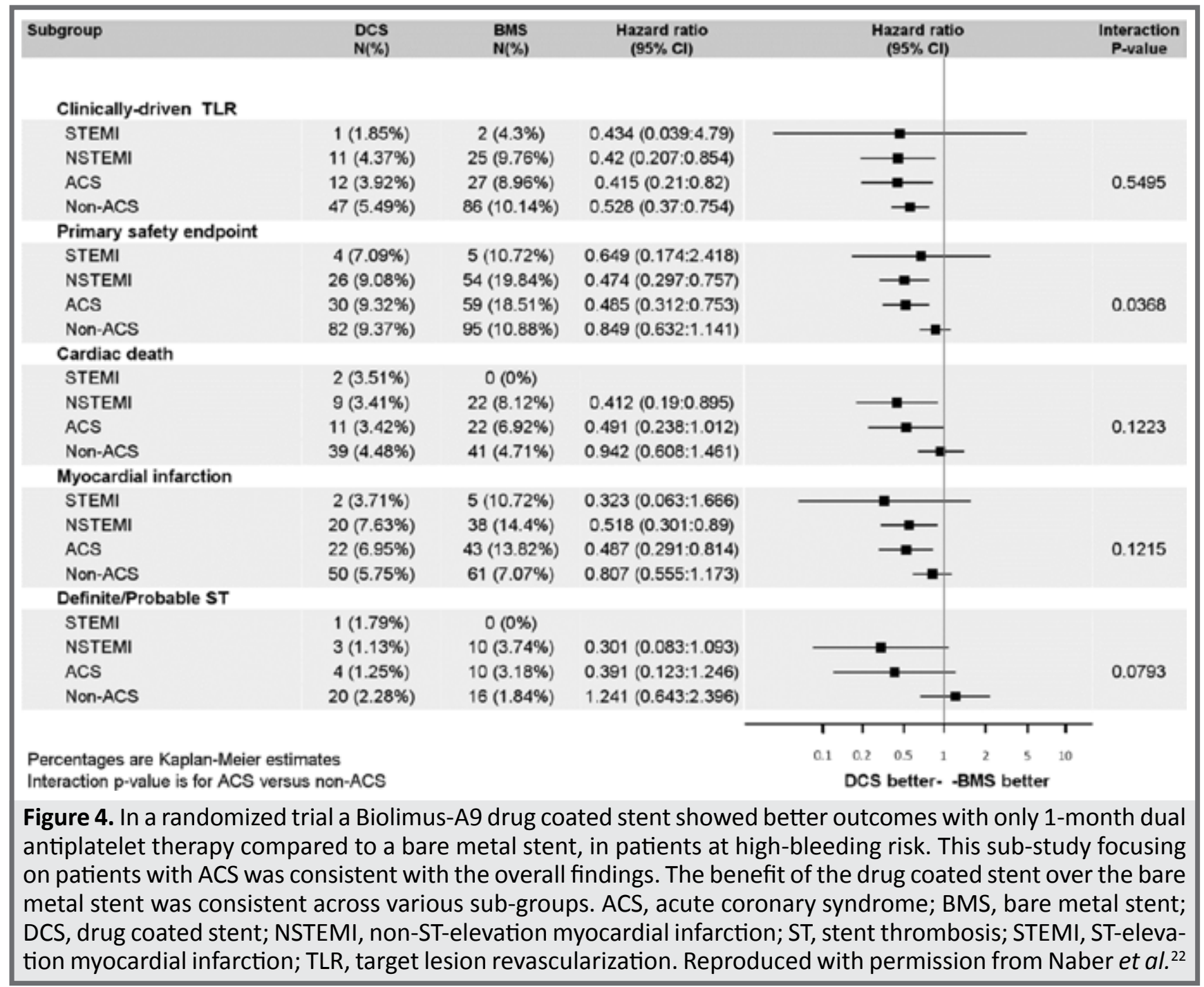

Naber CK, et al. Biolimus-A9 polymer-free coated stent in high bleeding risk patients with acute coronary syndrome: a Leaders Free ACS sub-study. Eur Heart J 2017; 38 (13): 961-969. doi: 10.1093/eurheartj/ehw203.

Reprinted with permission of Oxford University Press on behalf of the European Society of Cardiology.

$\mathrm{CNIC}$ trial ${ }^{29}$ suggested that the sooner metoprolol is administered in the course of an STEMI, the smaller the infarct size. However, the Early-BAMI tria| ${ }^{30}$ did not show any difference between STEMI patients randomized to early intravenous metoprolol or placebo. In this study, metoprolol reduced the incidence of malignant arrhythmias in the acute phase but was not associated with a reduction in the infarct size (peak and area under the creatine kinase curve).

\section{Lipid lowering agents}

Pharmacotherapy that reduces low-density lipoprotein cholesterol has consistently shown benefit for CV endpoints in patients with coronary artery disease. In an analysis of the IMPROVE-IT trial, the addition of ezetimibe to simvastatin not only reduced the rate of first primary endpoint but also reduced the rate of subsequent adverse CV endpoints in ACS patients. ${ }^{31}$ Meanwhile a new class of agents - proprotein convertase subtilisin/kexin type 9 inhibitors, which are approved for the treatment of familiar hypercholesterolemia, are under investigation in ACS patients (ClinicalTrials.gov Identifier: NCT01663402).

\section{Fibrinolysis in non- $\mathrm{PCl}$ capable hospitals}

The preferred reperfusion strategy for ACS patients presenting with STEMI is primary PCI. However, systemic fibrinolysis is still applied in STEMI patients in non-PCI capable hospitals if transfer for primary PCI would lead to unacceptable reperfusion delays. In a prospective multicentre STEMI registry, Carrillo et al..$^{32}$ compared the effect of in situ fibrinolysis vs. PCl transfer on 30-day mortality in a real-life consecutive cohort of 2470 STEMI patients. The study showed that patients in the transfer group whose from first medical contact (FMC) to device (PCI) time was achieved within 140 min were associated with significantly lower mortality (2.0\% for FMC-device $<99 \mathrm{~min}$, and $4.6 \%$ for FMC-device $99-140 \mathrm{~min}$; $P=0.01$ and $P=0.03$, respectively vs. fibrinolysis). In multivariable logistic regression analysis, reperfusion with fibrinolysis was an independent 30-day mortality predictive factor (OR: $1.91,95 \% \mathrm{Cl}: 1.01-3.50 ; P=0.04$ ). These results suggest, that transfer to a $\mathrm{PCl}$-capable hospital should be recommended, if FMC-device delay is less than $140 \mathrm{~min}$. 


\section{Revascularization strategies in ACS}

A third to half of ACS patients present with multi-vessel disease. The best treatment strategy and the optimal timing for non-culprit lesion $\mathrm{PCl}$ in ACS is a matter of debate. In the SMILE trial, ${ }^{33} 584$ patients with non ST elevation $\mathrm{Ml}$ with multi-vessel disease were randomized to single-stage complete revascularisation vs. multi-stage complete revascularization during the same hospitalization. No significant difference in the one-year incidence of cardiac death $(3.41 \%$ vs. $5.32 \%$ respectively, $P=0.27$ ) and $\mathrm{MI}(2.65 \%$ vs. $3.8 \%$ respectively, $P=0.46)$ was found between groups, although target vessel revascularisation was higher in the multi-stage group ( $8.33 \%$ vs. $15.2 \%$, $P=0.01$ ). However, there was no overall survival benefit of single- vs. multi-staged complete revascularisation.

If the culprit lesion of an ACS is located in an unprotected left main coronary artery (ULMCA), the optimal revascularization strategy is a matter of debate. In the DELTA all-comer, multinational registry ${ }^{34}$ the long-term outcomes of ACS patients with ULMCA treated with coronary artery bypass grafting (CABG) or PCl was investigated. In 379 ACS patients, no significant differences emerged for the composite endpoint of all-cause death, AMI, and cerebrovascular accident. As patients in this study received first-generation drug eluting stents a lower rate of target vessel revascularisation may be expected with newer-generation stents.

\section{Treatment of the elderly}

Schoenenberger et al. $^{35}$ analysed the use of guideline-recommended therapies and in-hospital outcomes of 13662 ACS patients $\geq 70$ years enrolled in the prospective Acute Myocardial Infarction in Switzerland (AMIS) cohort according to 4-year periods (2001-2004, 2005-2008, and 2009-2012). Between first and last 4-year period, $\mathrm{PCl}$ use increased as well as use of guideline recommended drugs. At the same time, in-hospital mortality of the overall population decreased from $11.6 \%$ in the first to $10.0 \%$ in the last 4 -year period, and in-hospital major adverse cardiac and cerebrovascular events from 14.4 to $11.3 \%$. This study indicates that increasing use of guideline-recommended therapies is appropriate in the elderly. It remains to establish whether this notion is also valid for octogenarians.

One aspect in the very elderly population was investigated by Tegn et al. ${ }^{36}$ They studied whether patients aged 80 years or older presenting with an ACS without ST-segment elevation would benefit from an early invasive strategy compared to an initially conservative management. During a median follow-up of 1.53 years, the primary outcome, a composite of $\mathrm{MI}$, need for urgent revascularization, stroke, and death, occurred in 93 (40.6\%) of 229 patients assigned to the invasive group and 140 (61.4\%) of 228 patients assigned to the conservative group (HR 0.53 [95\% $\mathrm{Cl} 0.41-0.69], P=0.0001$ ). The two strategies did not differ in terms of bleeding complications. In conclusion, in line with the ESC Guidelines, ${ }^{37}$ an invasive strategy in patients aged 80 years or older presenting with non-ST segment elevation MI was superior to a conservative strategy.

\section{Left ventricular assist device}

Patients who present with acute heart failure or cardiogenic shock refractory to reperfusion and medication may require mechanical circulatory support. In the INTERMACS registry patients who received a durable ventricular assist device (VAD) in the setting of an ACS were compared to those who received a VAD for non-ACS indications. ${ }^{38}$ In an unadjusted analysis the ACS group had higher early phase hazard (HR: $1.24 ; P=0.04$ ) but reduced late-phase hazard of death (HR: $0.57 ; P=0.04$ ) than the non-ACS group. Despite being more critically ill before VAD implantation, ACS patients had similar outcomes compared to non-ACS patients. Therefore, VAD implantation is a valuable strategy in ACS patients with cardiogenic shock or heart failure refractory to medical therapy.

\section{Outcomes in specific patient populations}

\section{Women}

An interesting scientific statement from the American Heart Association on ACS in women ${ }^{39}$ summarizes the main differences between men and women in this setting. In particular, it is highlighted that regardless of age, within a year of a first AMI, more women than men die; within 5 years of a first AMI, more women than men die, have heart failure, or suffer from a stroke, although the higher mortality for women compared with men is explained partially by differences in risk factors, clinical presentation, and treatment. Indeed, the prevalence of diabetes mellitus, heart failure, hypertension, depression, and renal dysfunction is higher in women compared with men. Compared with men, women more commonly present with NSTEMI and non-obstructive coronary artery disease. Women are also more likely to have unusual pathophysiological mechanisms of ACS such as spontaneous coronary artery dissection or coronary artery spasm.

\section{Smokers}

Symons et al..$^{40}$ assessed the effect of smoking in 471 STEMI patients by cardiac magnetic resonance. Smoking was associated with intramyocardial haemorrhage (IMH) at baseline even after correction for other factors associated with ischemia-reperfusion injury. Unexpectedly, smoking was an independent protective predictor against adverse left ventricular remodelling consistent with the 'smoker's paradox', although the presence of IMH at baseline abolished this paradoxical, beneficial effects of smoking. It remains to establish what mediates these intriguing protective effects of smoking in STEMI in order to identify new therapeutic targets.

\section{Rheumatoid arthritis}

Despite a wealth of studies describing an increased incidence of ACS in rheumatoid arthritis (RA), considerably less is known about the clinical characteristics and their association with short-term outcome of such ACS. Mantel et al. ${ }^{41}$ compared the clinical presentation of in- 


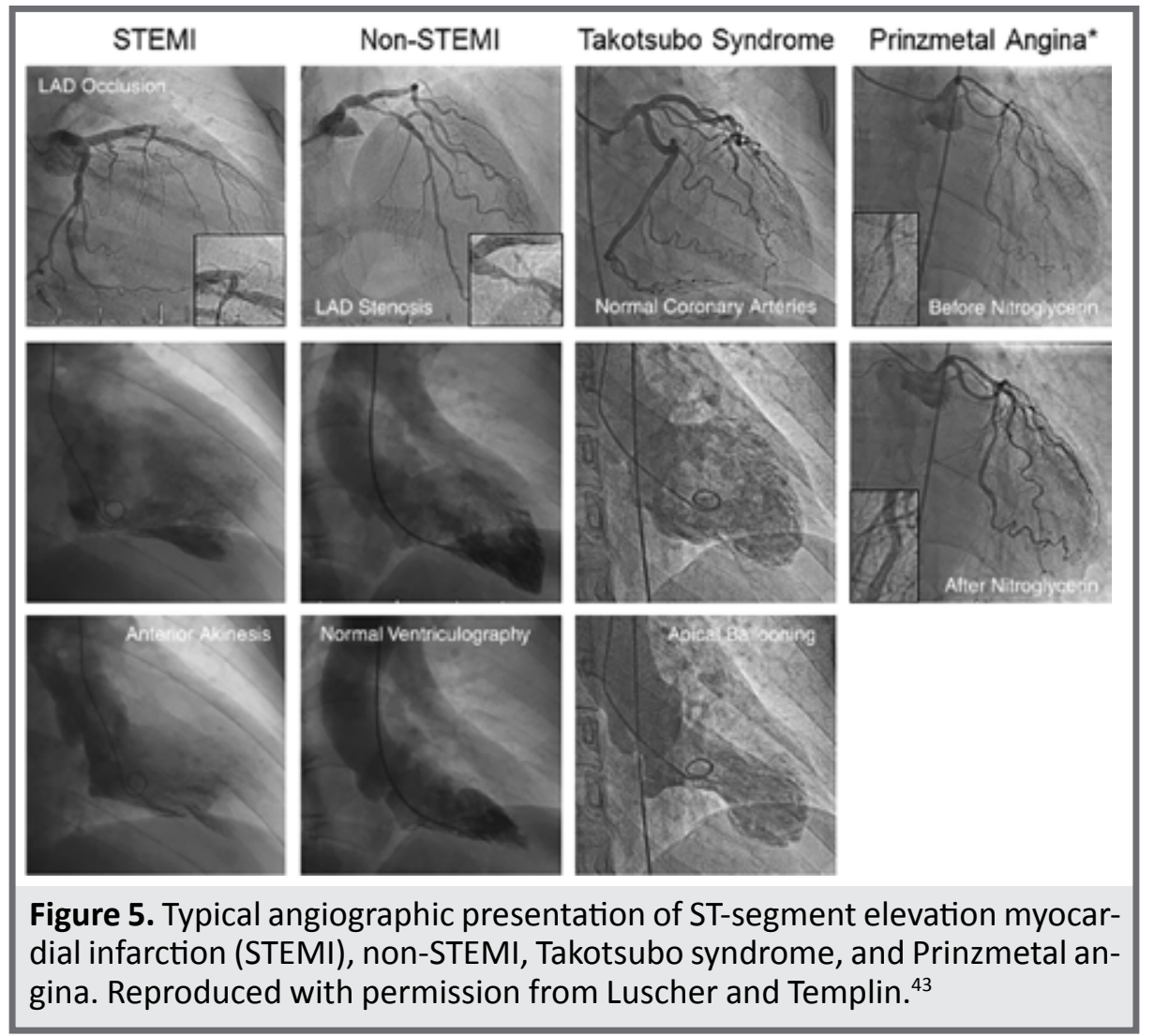

Lüscher TF, et al. Is takotsubo syndrome a microvascular acute coronary syndrome? Towards a new definition. Eur Heart J 2016; 37 (37): 2816-2820. doi: 10.1093/eurheartj/ehw057.

Reprinted with permission of Oxford University Press on behalf of the European Society of Cardiology.

cident ACS in a cohort of 1135 subjects with prevalent RA and in a cohort of 3184 matched general population comparators. RA subjects more frequently presented with SCD, STEMI, had higher levels of hsTn and higher frequencies of in-hospital complications compared with the general population comparators. Furthermore, the short-term mortality was higher among RA-associated ACS. The higher risk of RA-associated ACS is consistent with the important role of inflammation in the pathogenesis of ACS and should stimulate further research for the identification of personalized forms of treatment.

\section{Vasospastic angina}

Ahn et al. ${ }^{42}$ compared the outcomes of 188 patients with vasospastic angina and aborted SCD and 1844 patients with vasospastic angina without aborted SCD enrolled from 13 heart centres in South Korea. The former had a much higher risk of death than the latter. Predictors of SCD included age, hyperlipidaemia, family history of SCD, multi-vessel spasm, and left anterior descending artery spasm. It remains to establish which mechanisms make the myocardium more susceptible to malignant arrhythmias in these patients.

\section{Takotsubo syndrome}

Finally, an emerging notion is that ACS are not only caused by epicardial anatomic or functional alterations but also by coronary microvascular dysfunction (Figure
5). This seems to be the case, in particular for takotsubo cardiomyopathy (TTC) ${ }^{43}$ (Figure 6). To this regards, one study illustrated that TTC can be triggered by not only negative but also positive life events. ${ }^{44}$ While patient characteristics and also short- and long-term outcomes were similar between groups, the midventricular TTC type was more prevalent among the 'happy hearts' than among the 'broken hearts'. Presumably, despite their distinct nature, happy and sad life events may share similar final common emotional pathways, which can ultimately trigger TTC.

\section{Perspectives}

Major progress has been made in the understanding of ACS. In particular, novel data indicate that both basophils and eosinophils may play a pathogenetic role in ACS suggesting new potential therapeutic targets. Further efforts are also needed in the early diagnosis of ACS when it remains undetermined after optimal Tn assessment. The demonstration that GDF-15 predicts both ischemic and bleeding risk is exciting although its role in daily practice remains to be established. With regards to antithrombotic treatment, it remains challenging to tailor DAPT duration according to individual risk. Finally, the worse outcome of patients with RA as compared to those without RA indicates that the former need more aggressive forms of treatment to be defined in future studies. 


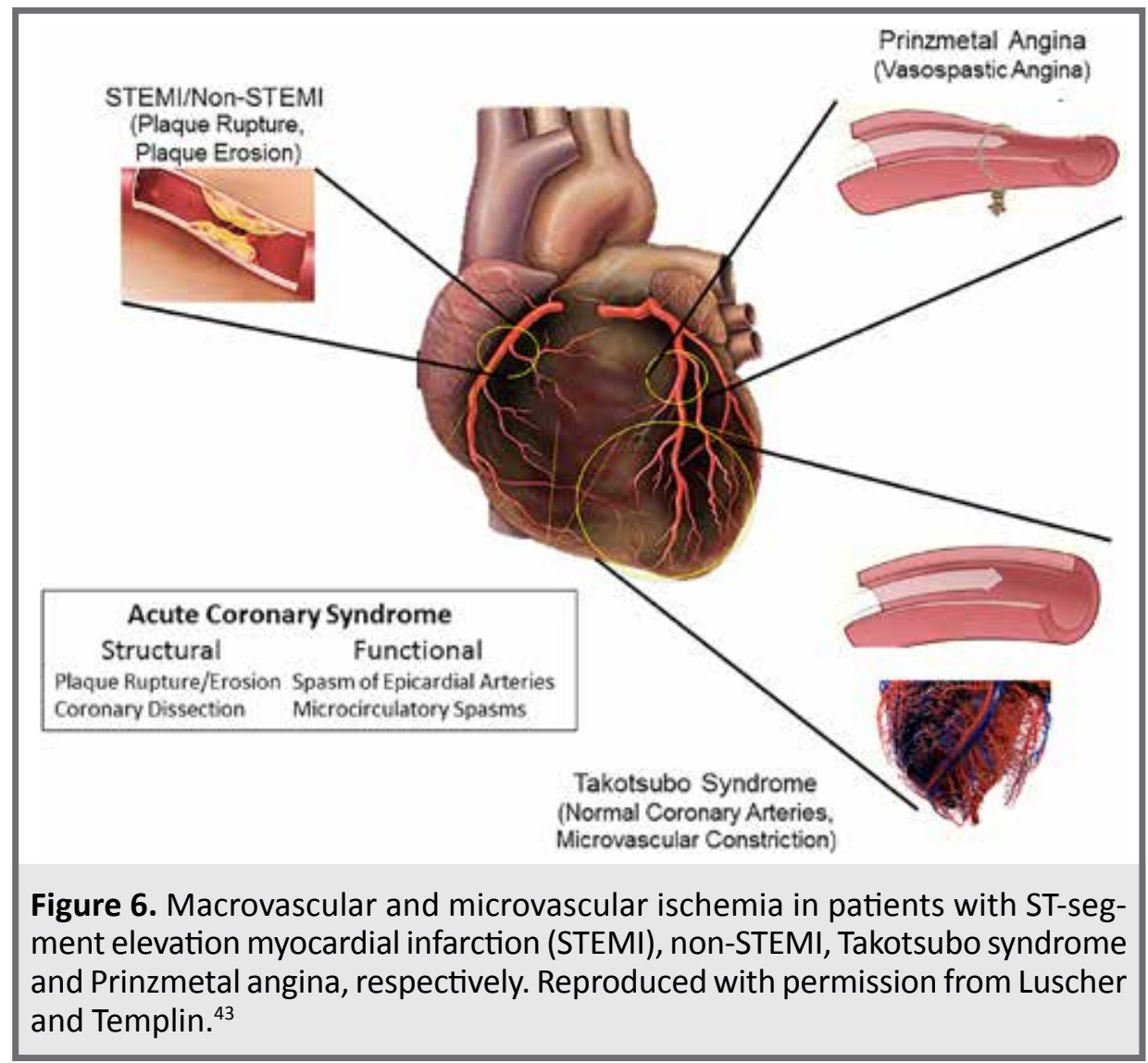

Lüscher TF, et al. Is takotsubo syndrome a microvascular acute coronary syndrome? Towards a new definition. Eur Heart J 2016; 37 (37): 2816-2820. doi: 10.1093/eurheartj/ehw057. Reprinted with permission of Oxford University Press on behalf of the European Society of Cardiology. ACS, acute coronary syndrome; NSTEMI, non-ST elevation myocardial infarction; PCI, percutaneous coronary intervention; STEMI, ST elevation myocardial infarction; VLST, very late stent thrombosis.

Conflict of interest: F. Crea has received speaker fees from Astra Zeneca and Servier. R.K. Binder has received speakers fees from AstraZeneca, is consultant for Biotronik and proctor for Boston Scientific. T.F. Lüscher has received institutional grants from Astra Zeneca, Eli Lilly, Medtronic, Boston Scientific and Biotronic as well as speaker fees from Astra Zeneca and Adjudication Committee fees from Bayer.

\section{References}

1. Niccoli, G., Calvieri, C., Flego, D., et al. Allergic inflammation is associated with coronary instability and a worse clinical outcome after acute myocardial infarction. Circ Cardiovasc Interv 2015;8:e002554.

2. Taniwaki, M., Radu, MD., Zaugg, S., et al. Mechanisms of very late drug-eluting stent thrombosis assessed by optical coherence tomography. Circulation 2016;133:650-660.

3. Horckmans, M., Ring, L., Duchene, et al. Neutrophils orchestrate post-myocardial infarction healing by polarizing macrophages towards a reparative phenotype. Eur Heart J 2017;38:187-197.

4. Shah, AS., Anand, A., Sandoval, Y., et al. High-sensitivity cardiac troponin I at presentation in patients with suspected acute coronary syndrome: a cohort study. Lancet 2015;386:2481-2488.

5. Pickering, JW., Greenslade, JH., Cullen, L., et al. Assessment of the European Society of Cardiology 0 hour/1 hour algorithm to rule out and rule in acute myocardial infarction. Circulation 2016;134:1532-1541.

6. Jaffe, AS., White, HD. Ruling In myocardial injury and ruling out myocardial infarction with the European Society of Cardiology (ESC) 1-hour algorithm. Circulation 2016;134:1542-1545.

7. Coskunpinar, E., Cakmak, HA., Kalkan, AK., Tiryakioglu, NO., Erturk, M., Ongen, Z. Circulating miR-221-3p as a novel marker for early prediction of acute myocardial infarction. Gene 2016;591:90-96.

8. Dedic, A., Ten Kate, GJ., Roos, CJ., et al. Prognostic value of coronary computed tomography imaging in patients at high risk without symptoms of coronary artery disease. Am J Cardiol 2016;117:768-774.

9. McNamara, RL., Kennedy, KF., Cohen, DJ., et al. Predicting inhospital mortality in patients with acute myocardial infarction. J Am Coll Cardiol 2016;68:626-635.

10. Hess, PL., Wojdyla, DM., Al-Khatib, SM., et al. Sudden cardiac death after non-st-segment elevation acute coronary syndrome. JAMA Cardiol 2016;1:73-79.

11. Hagstrom, E., James, SK., Bertilsson, M., et al. Growth differentiation factor-15 level predicts major bleeding and cardiovascular events in patients with acute coronary syndromes: results from the PLATO study. Eur Heart J 2016;37:1325-1333.

12. Bhatt, DL., Stone, GW., Mahaffey, KW., et al. Effect of platelet inhibition with cangrelor during $\mathrm{PCl}$ on ischemic events. N Engl J Med 2013;368:1303-1313.

13. Gutierrez, JA., Harrington, RA., Blankenship, JC., et al. The effect of cangrelor and access site on ischaemic and bleeding events: insights from CHAMPION PHOENIX. Eur Heart J 2016;37:1122-1130.

14. Meine, TJ., Roe, MT., Chen, AY., et al. Association of intravenous morphine use and outcomes in acute coronary syndromes: results from the CRUSADE Quality Improvement Initiative. Am Heart J 2005;149:1043-1049.

15. Parodi, G., Editor's choice-chest pain relief in patients with acute myocardial infarction. Eur Heart J Acute Cardiovasc Care 2016;5:277-281.

16. Kubica, J., Adamski, P., Ostrowska, M., et al. Morphine delays and attenuates ticagrelor exposure and action in patients with myocardial infarction: the randomized, double-blind, placebocontrolled IMPRESSION trial. Eur Heart J 2016;37:245-252.

17. Sahlen, A., Varenhorst, C., Lagerqvist, B., et al. Outcomes in patients treated with ticagrelor or clopidogrel after acute myocardial infarction: experiences from SWEDEHEART registry. Eur Heart J 2016.

18. Wallentin, L., Becker, RC., Budaj, A., et al. Ticagrelor versus clopidogrel in patients with acute coronary syndromes. N Engl J Med 2009;361:1045-1057. 
19. Rollini, F., Franchi, F., Hu, J., et al. Crushed Prasugrel tablets in patients with STEMI undergoing primary percutaneous coronary intervention: the CRUSH study. J Am Coll Cardiol 2016;67:1994-2004.

20. Udell, JA., Bonaca, MP., Collet, JP., et al. Long-term dual antiplatelet therapy for secondary prevention of cardiovascular events in the subgroup of patients with previous myocardial infarction: a collaborative meta-analysis of randomized trials. Eur Heart J 2016;37:390-399.

21. Urban, P., Meredith, IT., Abizaid, A., et al. Polymer-free drugcoated coronary stents in patients at high bleeding risk. N Engl J Med 2015;373:2038-2047.

22. Naber, CK., Urban, P., Ong, PJ., et al. Biolimus-A9 polymer-free coated stent in high bleeding risk patients with acute coronary syndrome: a Leaders Free ACS sub-study. Eur Heart J 2016; doi: 10.1093/eurheartj/ehw203.

23. Stone, GW., Witzenbichler, B., Guagliumi, G., et al. Bivalirudin during primary $\mathrm{PCl}$ in acute myocardial infarction. $\mathrm{N}$ Engl J Med 2008;358:2218-2230.

24. Steg, PG., van 'T Hof, A., Hamm, CW., et al. Bivalirudin started during emergency transport for primary PCI. N Engl J Med 2013;369:2207-2217.

25. Han, Y., Guo, J., Zheng, Y., et al. Bivalirudin vs heparin with or without tirofiban during primary percutaneous coronary intervention in acute myocardial infarction: the BRIGHT randomized clinical trial. JAMA 2015;313:1336-1346.

26. Shahzad, A., Kemp, I., Mars, C., et al. Unfractionated heparin versus bivalirudin in primary percutaneous coronary intervention (HEAT-PPCI): an open-label, single centre, randomised controlled trial. Lancet 2014;384:1849-1858.

27. Valgimigli, M., Frigoli, E., Leonardi, S., et al. Bivalirudin or unfractionated heparin in acute coronary syndromes. N Engl J Med 2015;373:997-1009.

28. Sirker, A., Mamas, M., Robinson, D., et al. Bivalirudin, glycoprotein inhibitor, and heparin use and association with outcomes of primary percutaneous coronary intervention in the United Kingdom. Eur Heart J 2016;37:1312-1320.

29. Garcia-Ruiz, JM., Fernandez-Jimenez, R., Garcia-Alvarez, A., et al. Impact of the timing of metoprolol administration during STEMI on infarct size and ventricular function. J Am Coll Cardiol 2016;67:2093-2104.

30. Roolvink, V., Ibanez, B., Ottervanger, JP., et al. B. Early intravenous beta-blockers in patients with ST-segment elevation myocardial infarction before primary percutaneous coronary intervention. J Am Coll Cardiol 2016;67:2705-2715.

31. Murphy, SA., Cannon, CP., Blazing, MA., et al. Braunwald, E., Reduction in total cardiovascular events with ezetimibe/simvastatin post-acute coronary syndrome: the IMPROVE-IT trial. J Am Coll Cardiol 2016;67:353-361.

32. Carrillo, X., Fernandez-Nofrerias, E., Rodriguez-Leor, O., et al. Early ST elevation myocardial infarction in non-capable percutaneous coronary intervention centres: in situ fibrinolysis vs. percutaneous coronary intervention transfer. Eur Heart J 2016;37:1034-1040.

33. Sardella, G., Lucisano, L., Garbo, R., et al. Single-staged compared with multi-staged PCl in multivessel NSTEMI patients. The SMILE Trial. J Am Coll Cardiol 2016;67:264-272.
34. Pyxaras, SA., Hunziker, L., Chieffo, A., Meliga, E., Latib, A., Park, SJ., Onuma, Y., Capranzano, P., Valgimigli, M., Narbute, I., Makkar, RR., Palacios, IF., Kim, YH., Buszman, PP., Chakravarty, T., Sheiban, I., Mehran, R., Margey, R., Agnihotri, A., Marra, S., Capodanno, D., Leon, MB., Moses, JW., Fajadet, J., Lefevre, T., Morice, MC., Erglis, A., Tamburino, C., Alfieri, O., Serruys, PW., Colombo, A., Naber, CK., Long-term clinical outcomes after percutaneous coronary intervention versus coronary artery bypass grafting for acute coronary syndrome from the DELTA registry: a multicentre registry evaluating percutaneous coronary intervention versus coronary artery bypass grafting for left main treatment. Eurolntervention 2016;12:e623-e631.

35. Schoenenberger, AW., Radovanovic, D., Windecker, S., et al. Temporal trends in the treatment and outcomes of elderly patients with acute coronary syndrome. Eur Heart J 2016;37:1304-1311.

36. Tegn, N., Abdelnoor, M., Aaberge, L., et al. After Eighty study i. Invasive versus conservative strategy in patients aged 80 years or older with non-ST-elevation myocardial infarction or unstable angina pectoris (After Eighty study): an open-label randomised controlled trial. Lancet 2016;387:1057-1065.

37. Roffi, M., Patrono, C., Collet, JP., et al. Management of Acute Coronary Syndromes in Patients Presenting without Persistent STSEotESoC. 2015 ESC Guidelines for the management of acute coronary syndromes in patients presenting without persistent ST-segment elevation: task force for the management of acute coronary syndromes in patients presenting without Persistent ST-segment elevation of the European Society of Cardiology (ESC). Eur Heart J 2016;37:267-315.

38. Acharya, D., Loyaga-Rendon, RY., Pamboukian, SV., et al. Ventricular assist device in acute myocardial infarction. J Am Coll Cardiol 2016;67:1871-1880.

39. Mehta, LS., Beckie, TM., DeVon, HA., et al. American Heart Association Cardiovascular Disease in W, Special Populations Committee of the Council on Clinical Cardiology CoE, Prevention CoC, Stroke N, Council on Quality of C, Outcomes R. Acute myocardial infarction in women: a scientific statement from the American Heart Association. Circulation 2016;133:916-947.

40. Symons, R., Masci, PG., Francone, M., et al. Impact of active smoking on myocardial infarction severity in reperfused ST-segment elevation myocardial infarction patients: the smoker's paradox revisited. Eur Heart J 2016;37:2756-2764.

41. Mantel, A., Holmqvist, M., Jernberg, T., Wallberg-Jonsson, S., Askling, J. Rheumatoid arthritis is associated with a more severe presentation of acute coronary syndrome and worse short-term outcome. Eur Heart J 2015;36:3413-3422.

42. Ahn, JM., Lee, KH., Yoo, SY., et al. Prognosis of variant angina manifesting as aborted sudden cardiac death. J Am Coll Cardiol 2016;68:137-145.

43. Luscher, TF., Templin, C. Is takotsubo syndrome a microvascular acute coronary syndrome? Towards of a new definition. Eur Heart J 2016;37:2816-2820.

44. Ghadri, JR., Sarcon, A., Diekmann, J., et al. Happy heart syndrome: role of positive emotional stress in takotsubo syndrome. Eur Heart J 2016;37:2823-2829. 